\title{
Espaços Heterotópicos, Imagens Sobrepostas: Encontros entre Arte, Loucura e Memória
}

Heterotopical Spaces, Overlapping Images: Meetings Between Art, Madness and Memory

Espacios Heterotópicos, Imágenes Sobrepuestas:

Encuentros entre Arte, Locura y Memoria

Tania Mara Galli Fonseca, Andresa Ribeiro Thomazoni, Vivian Lockmann \& Vitor Butkus Rio Grande do Sul

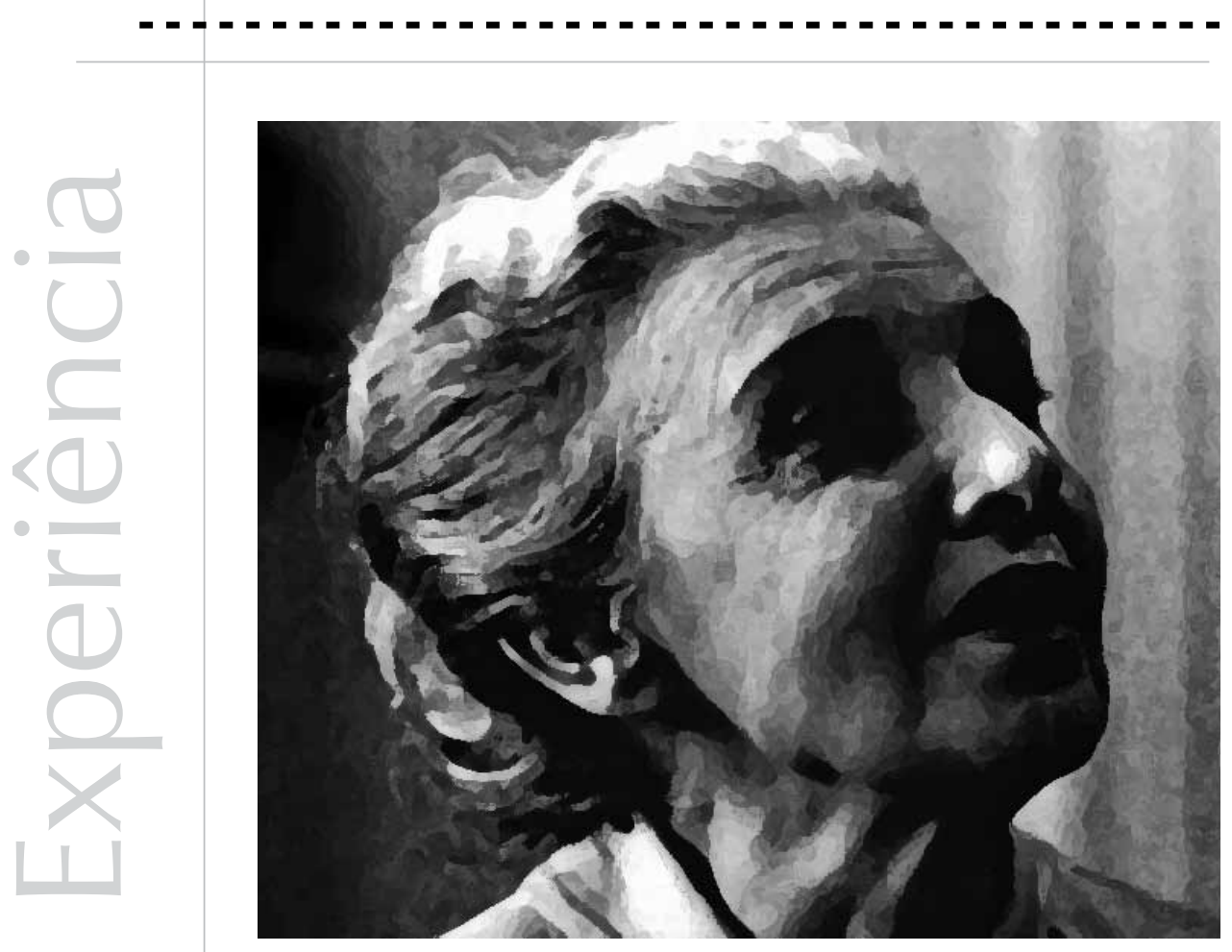


Resumo: O tema deste trabalho consiste no processo de catalogação das obras produzidas na Oficina de Criatividade Nise da Silveira, freqüentada por internos do Hospital Psiquiátrico São Pedro, situada em Porto Alegre, Rio Grande do Sul. Durante os 17 anos de sua existência, essa oficina foi se instaurando como um lugar contra o esquecimento, onde temporalidades singulares puderam resistir, fazendo-se obra ao tempo sem duração que insiste em se instituir na cidade globalizada. O trabalho de catalogação vem se desenvolvendo como produção coletiva (extensionista) que reúne a equipe do hospital e estudantes de diversas áreas, como artes, Psicologia e História (universidades pública e privada do RS). Foi identificada a existência de no mínimo quatro coleções significativas do ponto de vista do que se denomina Arte Reclusa ou Arte Bruta. Tais produções, que constituem um inestimável patrimônio imaterial, carecem, entretanto, de preservação e catalogação pertinentes para que venham a se constituir em reserva técnica para a pesquisa em diversos domínios, como os da saúde, educação e artes. A organização desse acervo, assim, acontece como inseparável de uma ética que vem buscar na obra o testemunho de subjetividades, tendo como matéria a afirmação da diferença em sua positividade.

Palavras-chave: Arte. Loucura. Memória. Museologia.

Abstract: The theme of this article is the process of cataloging of the works that have been produced in the Studio of Creativity Nise da Silveira, which is attended by interns of the Psychiatric Hospital São Pedro, in Porto Alegre, Rio Grande do Sul. During 17 years, since its foundation, this studio has been established as a place against oblivion, where singular temporalities can resist, through artistic creation, in spite of the time without duration that distinguishes the globalized cities. The process of cataloging has been developed as a collective production, congregating the hospital staff and the students from several areas, such as arts, Psychology and History (from public and private local universities). At least four significant collections, in the perspective of so-called Art Brut, were identified. These collections, which constitute an inestimable immaterial patrimony, require appropriate preservation and organization in order to become a technical reserve for research. Therefore the organization of these collections has been moved by an ethic purpose that considers the works of art testimonies of subjectivities, claiming the difference in its positivity.

Keywords: Art. Madness. Memory. Museology.

Resumen: El tema de este trabajo consiste en el proceso de catalogación de las obras producidas en el Taller de Creatividad Nise Silveira, frecuentada por internos del Hospital Psiquiátrico San Pedro, situada en Porto Alegre, Rio Grande do Sul. Durante los 17 años de su existencia, ese taller fue instaurándose como un lugar contra el olvido, donde temporalidades singulares pudieron resistir, haciéndose obra al tiempo sin duración que insiste en instituirse en la ciudad globalizada. El trabajo de catalogación viene desarrollándose como producción colectiva (extensionista) que reúne el equipo del hospital y estudiantes de diversas áreas, como artes, Psicología e Historia (universidades públicas y particulares de Rs). Fue identificada la existencia de por lo menos cuatro colecciones significativas del punto de vista de lo que se denomina Arte Recluso o Arte Bruto. Tales producciones, que constituyen un inestimable patrimonio incorpóreo, carecen, por otro lado, de preservación y catalogación pertinentes para que vengan a constituirse en reserva técnica para la pesquisa en diversos dominios, como los de la salud, educación y artes. La organización de ese acervo, así, acontece como inseparable de una ética que viene a buscar en la obra el testimonio de subjetividades, teniendo como materia la afirmación de la diferencia en su positivismo.

Palabras clave: Arte. Locura. Memoria. Museología.

Este trabalho se insere no movimento prático-reflexivo iniciado pela proposta de organização do acervo da Oficina de Criatividade Nise da Silveira, criada em 1990, num dos pavilhões do mais antigo hospício gaúcho, o Hospital Psiquiátrico São Pedro (HPSP), em Porto Alegre. O trabalho propõe-se a mapear o território dessa ação, pioneira no Estado. A catalogação do acervo foi iniciada no ano 2007, inserindo-se no conjunto de ações desenvolvidas em caráter de parceria e extensão entre instituições do HPSP, universidade pública e privada do
Rio Grande do Sul (estudantes de diversas áreas, como artes, Psicologia e História). Entendendo que tal iniciativa ocorre em meio a processos em andamento, busca-se, aqui, realizar um recorte desses processos.

Em relação ao contexto local, cabe aqui trazer as linhas gerais do lugar em questão. O pavilhão que hoje serve de espaço para as atividades da Oficina faz saltar à vista daqueles que o visitam muito mais que as imagens de arte, objetos da catalogação. Essas imagens estão emolduradas por paredes que 
1 O termo Arte

Bruta foi criado por Jean Dubuffet, artista plástico, em 1948, que lança a Compagnie de L'Arte Brut, com um museu em Lausanne, na Suíça. Essa expressão refere-se à busca de obras que escapem o mais possível aos condicionamentos culturais e que partam de posturas de espírito verdadeiramente inéditas, uma busca que não é feita em escolas, mas entre os homens comuns, liberta de todos os compromissos que alternam os mecanismos nas produções profissionais. trazem, além de resquícios de tinta, as marcas que testemunham a história da loucura e da psiquiatria. Vêm à vista imagens que conservam, no presente, histórias da relação da cidade de Porto Alegre com os cidadãos para os quais, nessa cidade, se construiu esse lugar especial: os loucos. A primeira parte deste trabalho dedica-se, então, a recontar um pouco dessa história, partindo dos índices que a fazem durar na atualidade do nosso contexto de trabalho.

Trazer à tona essas marcas históricas colocanos num horizonte de discussão que não se restringe ao contexto local. As paredes do HPSP participaram, em sua construção planejada, de um movimento político e social ressonante das políticas de urbanização e racionalização que produziram os modos urbanos de vida. Ademais, tais paredesmuros, não mais tão brancos, ilustram e conformam as recentes movimentações da reforma psiquiátrica no que toca às problematizações contemporâneas da loucura. Podendo ser considerada um fruto dos novos modos de conceber o louco no contexto urbano, a Oficina de Criatividade Nise da Silveira traz às vistas de hoje um enorme volume de imagens, cujos destinos nos forçam a pensar. É assim que a singular sobreposição de imagens, experimentada no ato dessa catalogação, nos convoca a instaurar as vias de sua disponibilização no contexto artístico e investigativo atual, tarefa essa sobre a qual o presente estudo busca refletir, traçando as linhas que conectam e tensionam esse acervo de memórias da loucura com a complexidade cultural contemporânea.

Propomos um exercício de pensamento capaz de escavar as antigas paredes brancas, escavar a insurgência de outros espaços na clausura do hospital, resgatar a memória da Arte Bruta ${ }^{1}$ ali produzida, num esforço capaz de extrair as potências que ali se encontram e resistem ao tempo, tal como Walter Benjamin nos fala, a memória como meio de exploração ao passado e a tudo aquilo que a atravessa.

\begin{abstract}
A língua tem indicado inequivocamente que a memória não é um instrumento para a exploração do passado; é, antes, o meio. É o meio onde se deu a vivência, assim como o solo é o meio no qual as antigas cidades estão soterradas. Quem pretende se aproximar do próprio passado soterrado deve agir como um homem que escava. ... A rigor, épica e rapsodicamente, uma verdadeira lembrança deve, portanto, ao mesmo tempo, fornecer uma imagem daquele que se lembra, assim como um bom relatório arqueológico deve não apenas indicar as camadas das quais se originam seus achados, mas também, antes de tudo, aquelas outras que foram atravessadas anteriormente. (Benjamin, 1997, p. 239)
\end{abstract}

\section{Paredes brancas em Porto Alegre}

O espaço que hoje abriga o acervo da Oficina de Criatividade do HPSP corresponde ao segundo andar do pavilhão central do centenário hospital. As obras estão acondicionadas em prateleiras de uma ampla sala, em cujo centro encontramos uma mesa. Acima dessa mesa, afixado no teto, vemos um portentoso braço metálico, que sustenta, em sua extremidade, um conjunto de lâmpadas. São lâmpadas cirúrgicas. A mesa central tem as dimensões suficientes para acolher um corpo humano, deitado.

A construção desse prédio data de 1884, época na qual a administração municipal de Porto Alegre tomava diversas medidas para racionalizar a malha urbana, organizando os fluxos e criando, para isso, novos pólos institucionais e novas condições de circulação. Segundo Costa (2005), os desarrazoados eram, até então, separados do convívio social e confinados na Santa Casa de Misericórdia ou nas cadeias. Às vésperas do século XX, Porto Alegre crescia como metrópole regional. Reverberavam nessa cidade os ideais positivistas de Auguste Comte, trazidos da Europa pela elite intelectualizada. Nesse contexto, a criação de um hospício encontrou 
a adesão de governantes e da população, que se viam justificados a adotar modelos urbanísticos importados da modernidade européia.

Numa área afastada do centro da cidade, foi erguido o prédio do HPSP, composto de seis pavilhões, com seus respectivos pátios. No início do século, então, os loucos da cidade - e de várias partes do Rio Grande do Sul - já tinham o seu destino. Eles eram alocados nos seis pavilhões do hospital, seguindo-se aí uma distribuição condizente com as classificações nosológicas vigentes.

As paredes dessa sólida construção serviram, num mesmo movimento, para separar os loucos do resto da cidade e para constituir um ambiente de tratamento da loucura. Tornados pacientes, essas pessoas recebiam tratamentos cuja finalidade era o apagamento de subjetividades insuportáveis à dinâmica social. O pavilhão que hoje abriga o acervo era o centro cirúrgico do hospital, espaço onde os corpos, depois de bem sedados, eram submetidos a intervenções com fins terapêuticos.

As paredes brancas formaram um ambiente asséptico e neutro de práticas, cuja neutralidade era atestada pela suposta universalidade do saber médico-científico, e cuja finalidade estava em consonância com uma regularidade dos modos de viver em sociedade. O lugar do acervo guarda essa memória na brancura esmaltada dos seus azulejos e no mobiliário cirúrgico, que não nos deixam esquecer as vigas concretas e abstratas que sustentaram a criação de nosso espaço de trabalho.

\section{Outros pigmentos}

No decorrer do século XX, as mudanças epistemológicas que sustentaram diferentes nosologias e intervenções no que concerne à loucura se expressaram em configurações espaciais do hospital em questão. Em meados desse período, o HPSP tinha, dentro de suas fronteiras, algo como uma pequena comunidade. Hortas e manufaturas mantinham os moradores do hospital ocupados, o que reflete uma diferença no tratamento da loucura. Assim, os pacientes fora dos estados de surto e catatonia tinham sua energia aplicada nessas atividades sempre, claro, sob os olhares atenciosos e vigilantes dos médicos e funcionários responsáveis pelo bom andamento dos trabalhos. Num esforço imaginativo, podemos considerar provável que os pequenos reparos nas salas pavilhonares tenham sido realizados por moradores-pacientes - claro, desde que devidamente medicados e instruídos pelo corpo de funcionários.

Já no final do século, uma outra política pública vai nortear os modos de lidar com a loucura social. A reforma psiquiátrica implantada em âmbito nacional acompanhou um movimento de problematização das relações saúde-loucura que envolveu um amplo campo de disciplinas e instituições. Outros âmbitos, além do médico, passaram a se sentir convocados pela discussão das margens instituídas entre o normal e o patológico, propiciando as condições necessárias para uma revisão dos mecanismos sociais de gestão da saúde mental. Ganhou corpo, assim, uma tendência de descentralização dos locais de atendimento ao portador de sofrimento psíquico, em que se refletia também a intenção de que a sociedade, em seus vários estratos, contribuísse para a inclusão e o respeito da diferença.

Centenário, o HPSP deixa de ser a destinação de pacientes psiquiátricos, que passam a ser tratados em serviços substitutivos espargidos pela cidade. A rede de serviços substitutivos inclui unidades que, em geral, não se destinam à moradia, onde os pacientes são recebidos por equipes multidisciplinares compostas de psicólogos, médicos, pedagogos, terapeutas ocupacionais, assistentes sociais e arteeducadores. Assim, o atendimento ao doente mental se torna mais complexo, ao mesmo tempo em que, do HPSP, milhares de 
Acreditamos, com Weinreb (2003, p. 62), que:

as idéias de Osório César e Nise da Silveira sensibilizaram para um outro olhar, um olhar para uma outra direção, a da inclusão, assim ressignificando conceitos sobre arte e loucura. Essa proposta continua ainda hoje presente e necessária, questionando em seu cerne as atitudes que passam para os depósitos (manicômios) da civilização tudo o que não se quer ver. Portanto, um novo olhar é necessário, através de um movimento dos sentidos que permita ver esse outro lado. pacientes são realocados para suas moradas de origem, sob a responsabilidade dos respectivos familiares.

Em 1990, já no contexto das mudanças que vão resultar na reforma psiquiátrica, é criada, no São Pedro, a Oficina de Criatividade Nise da Silveira. Esta se configura como um espaço de liberdade de expressão, a partir de materiais e conteúdos escolhidos pelos próprios usuários. Ali são produzidos desenhos, pinturas, modelagens, bordados e escritas, sendo que os suportes procedem de sucata recolhida pelos profissionais e técnicos que lá atuam. Lápis de cor, giz de cera, hidrocor, tinta têmpera, sucata, revistas, linhas, panos e argila são alguns dos materiais utilizados na confecção dos trabalhos. A iniciativa de criação da Oficina, bem como a atual organização por que passa seu acervo, encontram inspiração no Museu de Imagens do Inconsciente, situado no Rio de Janeiro e fundado em 1952 pela psiquiatra Dra. Nise da Silveira, e também no Museu Osório César, localizado em São Paulo, fundado em 1985 por Maria Heloísa Ferraz. Acreditamos, com Weinreb (2003, p. 62), que:

as idéias de Osório César e Nise da Silveira sensibilizaram para um outro olhar, um olhar para uma outra direção, a da inclusão, assim ressignificando conceitos sobre arte e loucura. Essa proposta continua ainda hoje presente e necessária, questionando em seu cerne as atitudes que passam para os depósitos (manicômios) da civilização tudo o que não se quer ver. Portanto, um novo olhar é necessário, através de um movimento dos sentidos que permita ver esse outro lado.

A Oficina propicia a adição de outras cores num espaço marcado pela neutralidade. Nesse seu tempo de funcionamento, ela deu lugar à confecção de cerca de 100.000 trabalhos. Recentemente, num estágio inicial de organização, esses trabalhos foram separados por ano e por autoria. Além disso, foram recolhidas e armazenadas outras espécies de documentos, como fotos, relatórios e catálogos de exposições que, por seu caráter de registro histórico, merecem ser disponibilizados para pesquisadores. Esse constitui o grande volume de material que, atualmente, está em via de ser catalogado através da criação de um banco de dados digitalizado.

Do trabalho inicial de organização das obras, que se encontravam acumuladas aleatoriamente no espaço do acervo, foram identificadas quatro coleções de inegável consistência estética que, hoje, a par da continuidade daquele outro processo ininterrupto, pois a produção de obras pelos freqüentadores da Oficina é ainda constante e diária, estão merecendo nossa atenção. Essas coleções, de autoria de Luiz Silveira Guides, Natália Leite, Frontino Vieira e Cenilda Ribeiro, constituem uma arte voltada para os afectos do tempo. É por elas que se inicia a alimentação do banco de dados, que, posteriormente, poderá ser o suporte de maior visibilidade e circulação dessas obras.

Cronologicamente, as relações da arte com a psiquiatria e a Psicologia datam do século XIX, quando apareceram as primeiras referencias teóricas sobre o assunto e foram introduzidas nos hospitais psiquiátricos algumas atividades de natureza artística ou artesanato. No campo da psiquiatria, percebe-se que as primeiras ligações entre elas vão oscilar entre as diversas linhas terapêuticas e com as comparações com a arte de vanguarda (Ferraz, 1998).

Neste final de milênio, é fácil notar-se ainda o impacto da produção criadora dos doentes mentais no imaginário das pessoas e nos trabalhos de intelectuais e artistas, mas é muito pouco o que encontramos de efetivamente produzido em termos de publicação e pesquisas. Ressaltam-se as traduções de obras como a Prinzhorn (1995) e trabalhos como de John M. MacGregor, The Discovery of the Art of the Insane (1992) e Depression and the Spiritual in Modern Art-Homage to Miro. No Brasil, como veremos mais adiante, estamos procurando marcar esse espaço por meio de pesquisas e eventos onde seja possível discutir e analisar as produções e suas influências (Ferraz, 1998, p. 27). 
A arte

transcende, ou melhor, ignora a diferença entre as frágeis fronteiras da sanidade e da loucura como ignora a diferença entre primitivos e modernos. Nas composições desses

artistas, cujo diagnóstico é freqüentemente sem esperança

(esquizofrenia incurável), cumprem-se as duas exigências da arte: "ser a destruição da comunicação comum e ser a criação de uma outra comunicação", isto é, ser a instauração de uma comunicação incomum.

(Frayze-Pereira, 2003, p. 197)
O trabalho de organização do acervo visa dar o tratamento adequado às obras ali contidas, possibilitando a criação de espaços de diálogo e pesquisa que envolvam a temática da arte e loucura. Através dessa documentação, será possível produzir e acumular conhecimento, divulgando-o por meio de exposições, cursos e publicações. Esse movimento faz parte da reforma psiquiátrica e exerce influência no processo de transformação dos espaços e dos métodos terapêuticos existentes.

A idéia de Art Brut é lançada pelo pintor Jean Dubuffet, que qualificou artisticamente, e pela primeira vez do ponto de vista da crítica, as criações dos não-profissionais, inclusive a dos pacientes psiquiátricos.

No grupo surrealista, os artistas André Breton, Paul Eluard e Max Ernst foram os primeiros a mostrar interesse pela manifestação espontânea dos psicóticos, estudando desenhos, poemas e outros escritos, da mesma maneira que os artistas expressionistas Breton e Max Ernst foram buscar no asilo essas manifestações artísticas, visitando e também trabalhando em diversos hospitais psiquiátricos. A descoberta da arte dos psicóticos interessa especialmente a artistas como Paul Klee e Max Ernst, que se mostram sensibilizados ao conhecer os desenhos e pinturas dos loucos pela riqueza imaginativa, pelos seus simbolismos e espontaneidade (Ferraz, 1998).

A arte transcende, ou melhor, ignora a diferença entre as frágeis fronteiras da sanidade e da loucura, como ignora a diferença entre primitivos e modernos. Nas composições desses artistas, cujo diagnóstico é freqüentemente sem esperança (esquizofrenia incurável), cumprem-se as duas exigências da arte: "ser a destruição da comunicação comum e ser a criação de uma outra comunicação", isto é, ser a instauração de uma comunicação incomum. (Frayze-Pereira, 2003, p. 197)

\section{Sobreposições heterotópicas}

Fica, dessa maneira, demarcado um conjunto complexo de imagens com as quais tem de se lidar no trabalho de catalogação do acervo. Para além da materialidade de cada obra e da visualidade de cada imagem, cabe recebê-las como expressões atravessadas por uma série de movimentos, que as fazem durar como potências. Assim, essas obras concatenam tendências que ultrapassam a individualidade de seus autores. São os resíduos visíveis de um passado histórico que ainda se move nas conformações da experiência contemporânea.

O processo pelo qual se individualizou a forma "museu" cumpriu a tendência moderna de compartimentar o espaço, com vistas a uma ordem geral. As práticas embrionárias da musealização consistiram, há 400 anos, na reunião de obras de arte em ambientes de ateliê, onde elas eram justapostas a obras ainda em processo (Janeira, 2005). Mais tarde, as plataformas políticas liberais suscitaram a criação de espaços públicos destinados a disponibilizar tais bens culturais para um público irrestrito.

A prática de reunir acervos se desloca, então, da casa do artista para espaços caracterizados pelo acúmulo: acúmulo de tempo e coleção de processos, que são deslocados de seus territórios gerativos e reterritorializados na malha social compartimentada. $\mathrm{O}$ ato de catalogar, assim considerado, acha-se imerso nos paradoxos que o sistema capitalista coloca à atitude criadora. Acreditando, com Deleuze e Guattari (1996), que é nos limites do capitalismo que se produzem as linhas de fuga, e não na dialética de polarização, vemos ainda a possibilidade de que o gesto atual de catalogação venha a favorecer verdadeiros acoplamentos com os devires minoritários expressos nas obras.

Em seu texto "Outros Espaços", Foucault (2001, p. 419) define os museus como os lugares onde se acumulam registros de "todos os tempos, todas as épocas, todas as formas, todos os gostos", ali inseridos por uma vontade, humana e moderna, de localizar-se 
acima de todos esses tempos e dessas épocas, de fazer-se senhor das formas e dos gostos possíveis. Por outro lado, tal caráter é lançado nesse texto quase como um detalhe, ou um modo de ser, já que o propósito do autor, aí, é propor as bases de estudo de espaços chamados por ele de heterotopias.

Utopias e heterotopias, para Foucault (2001), referem-se a posicionamentos paradoxais em relação àquelas economias espaciais praticadas na contingência dos cotidianos urbanos. São paradoxais porque são vividos na contemporaneidade de tais contingências histórico-sociais, mas, de alguma forma, são lançadas para fora de si mesmas. A utopia mantém, com os espaços reais, uma relação geral de analogia direta ou inversa; lança esses espaços, portanto, num movimento destinado a alcançar um ideal que eles ainda não concretizaram. As macropolíticas urbanas, tendo como ideal bem figurado o bem-estar de seus habitantes incluídos, lançam a malha urbana no interior de um sistema utópico. Essa economia dos espaços faz surgir, entrementes, situações concretas regidas por políticas que escapam ao controle do Estado, seja ele central ou descentralizado - as heterotopias.

Diversamente das utopias, que seriam principalmente abstrações que operam em determinados lugares, as heterotopias são localizáveis no tempo e no espaço. Porém, em relação a esses posicionamentos, as heterotopias concretizam uma contestação mítica e real, sendo lugares de afirmação de uma certa vida social, instituinte e diferenciante. Assim, o espaço praticado do museu, lugar do acúmulo instituído da produção artística, é espaço-tempo de processos criativos que duram, no sentido bergsoniano do termo, o da duração em que o ser desse espaço-tempo, ao se conservar, se diferencia (Bergson, 1959).

$\mathrm{Na}$ catalogação do acervo da Oficina de Criatividade, é, portanto, ética e esteticamente interessante a vivência crítica possibilitada pela criação de um arquivo museológico. A genealogia proposta por Janeira (2005), dando-nos ver as práticas pioneiras daquilo que agora atualizamos, oferece-nos nostalgicamente as imagens de um tempo em que a arte era oferecida ao público no lugar mesmo de seu curso processual. A imagem foucaultiana da heterotopia, considerando já os atuais arquivos de arte como espaços de fabulação criadora, dá-nos condições de ultrapassagem em relação à nostalgia.

Se, do ponto de vista de uma história linear, os colecionismos testemunham o surgimento de um sujeito globalizante e hegemônico, a história do presente nos mostra que os museus são os lugares de encontro com dimensões temporais não reconciliáveis com a cronologia dos vencedores. Tal situação se torna particularmente notável quando as obras que se propõe catalogar são criações animadas pela expressão de subjetividades exiladas do sistema utópico de formatação idealizada da vida. No horizonte aqui traçado, habitado por imagens sobrepostas - a própria matéria de nossa presente catalogação -, cabe considerar que as imagens do acervo testemunham histórias que desvirtuam aquelas histórias tidas como factuais. As imagens produzidas na Oficina - se é que têm histórias a contar - fazem durar narrativas diversas daquelas que se conservam nos arquivos da alta cultura.

Vilela (2000, p. 10), num estudo sobre a preservação da memória dos refugiados de guerra, sustenta: "Existe uma linguagem da evidência marcada nesses corpos que faz com que a verdade esteja não do lado do agressor, mas da vítima; só ela pode dizer de um sofrimento que não se comunica ou representa, apenas se exibe".

Contemporaneamente, há lugares onde se concentram essas imagens moventes que não são produzidas com a intenção de comunicarse com uma dada cultura estabelecida nem de representar uma realidade, com vistas 
a uma inserção ou a um reconhecimento. Os campos de refugiados são lugares de existências concretas, vidas das quais não é suficiente dizer que esperam por uma salvação ou uma inclusão. Na imagem de um corpo estirado no chão, a autora lê uma história que, ainda que incomunicável, dura.

Existem memórias de lugares, medos e resistência, lugares que, sendo não lugares, constituem heterotopias nas quais se define uma lógica paralela à do espaço legitimado, por referência ao qual se tornam enclaves. Os homens que os habitam - deslocados, asilados, refugiados - erguem-se rente ao medo. Há lugares que se confundem com o seu objecto: o corpo estendido, oblíquo ao céu, como se apenas pudesse existir assim. Lugares de morte. (Vilela, 2000, p. 9)

Podemos supor que as memórias dessas obras se referem ao espaço de exceção do hospital psiquiátrico, no qual se instala a produção de vidas nuas, "não a história dos vencedores, mas as ruínas e os restos, o que sobrou dos escombros da História" (Engelman, 2007, p. 55).

Dentre as quatro coleções de obras por que iniciamos o gesto de catalogar, duas delas têm os seus autores falecidos. As outras duas coleções ainda aumentam, a cada semana que passa. Seus autores são antigos moradores do hospital que, nas diversas fases das mudanças estabelecidas durante a reforma, não tiveram para onde retornar. Esses artistas, não dispondo de vínculos que pudessem amparar suas existências fora dos muros, agora habitam esse espaço definitivamente. As obras em que se constituem sua vida se desenrolam nesse espaço, tornado espaço de passagem pelas políticas antimanicomiais. Nesse endereço singular, eles testemunham uma exclusão do lugar social, e, ao mesmo tempo, essa existência-testemunha instaura, pela arte, um plano de vida.

Arte voltada para os aspectos do tempo, arte-pensamento que difere da arte- inteligência. Arte do vazio, espécie de contorno depois da explosão, arte que resiste ao esquecimento imposto pelos muros psiquiátricos, arte-testemunho de um desamparo absoluto e de uma longa história de normalização do anômalo. (Fonseca, 2005, p. 106)

Por artistas da margem, também denominamos, aqui, os autores das quatro coleções de obras que se tornam objeto de nossa ação extensionista. Referimo-nos, então, não a sujeitos que se situam nas extremidades, delimitando um dentro e um fora da cultura, mas à margem que marca um intermezzo, a algo que se desloca entre lógicas duras, sem pertencer a qualquer uma. Trata-se, a nosso ver, de um lugar que é, a um só tempo, absolutamente interior e exterior à máquina socio-cultural e que é forjado no próprio contexto no qual habitam os sujeitos que, então, delas escavam novas possibilidades de linguagem. Dessa perspectiva, torna-se artista aquele que trabalha na direção de um "pode ser", na atualização, portanto, das virtualidades imanentes ao seu próprio território existencial, que se transmuta por seu ato criador e por suas possíveis proliferações. Consideramos que tal produção artística criada no próprio seio daquilo que a pode aprisionar - é dotada de um caráter de resistência ativa que a torna peculiar, ética e politicamente significativa. Trata-se de uma produção artística relevante tanto por sua extensão quanto por seus significados, e pode ser tomada como um breve clarão que testemunha a existência de homens e mulheres que, apesar da impotência de suas existências, resistem em sua vontade de expressão e de relação viva com a realidade. Trata-se, enfim, de uma manifestação coletiva, que nos leva a perguntar sobre a força que ainda reside na impotência e sobre como esses corpos, sujeitados a tantos desígnios de um poder que os quer normalizar e negar, ainda dizem não ao seu silenciamento e apagamento socio-afetivo e cultural. 
2 Não-lugar é o termo cunhado por Marc Augé (2003) para dar conta de espaços onde se engendraria uma supermodernidade. Caracterizada pelo excesso de memória e pela intensa circulação midiática dessa memória, a supermodernidade se funda nesses outros espaços que não negam os seus excessos de tempo acumulado, mas os modulam na atualidade de sua proliferação.
As sombras surgem em superfícies onde é a partida que está na memória de todos os lugares de chegada. Existem corpos que não descrevem, mas inscrevem, nos seus movimentos, a transcendência na imanência de cada gesto. Esses corpos rasgam os lugares, tornam o não-lugar ${ }^{2}$ uma heterotopia. São, eles mesmos, lugares onde a convocação de sentido se faz em equilíbrio precário. (Vilela, 2000, p. 9)

Nas paredes rachadas do hospício, firmase um outro espaço, frágil ponto capaz de empreender fugas, esboçar novos estados, gestos inacabados. Marcel Duchamp dizia que o valor de uma obra se produz pelos efeitos que produz no mundo. As obras da Oficina nos falam sobre aqueles que pintaram as forças do tempo, as sensações em fluxos nos próprios corpos. É a entrega de seu tempo, em gestos subjetivos, na tentativa de confecção de uma nova realidade: "Produção de imagens de resistência e criação, eternizadas por um sofrimento que nunca cicatriza, por um abismo jorrante cujo magma é absorvido pela obra, como uma espécie de curativo do vazio" (Fonseca, 2007, p. 143).

As obras das coleções a que nos referiremos formam um conjunto que pode ser considerado um arquivo da memória que, ao ultrapassar o sentido de indícios registrados de biografias individuais, torna-se o documento que nos remete à necessidade de fazer a história do nosso presente, retomando os liames rompidos dos diálogos entre loucura e razão, cultura, ciência e vida. Mais do que biografias e rumos de vidas individuais extraviadas da retidão da normalidade, o que nos surpreende e interessa é a sua capacidade de expressão, sua resistência em manter-se dizendo algo quando todo o seu entorno lhes impõe esquecimento e letargia. Não nos interessa tomar as obras de arte para desentranhar-Ihes possíveis interpretações inconscientes que viriam a auxiliar em processos terapêuticos. Nosso enfoque, neste momento, recai na obra como arte e como incessante manifestação vital dos rumores de forças que habitam ou habitaram os corpos dos autores. Encorajamo-nos a encontrar, para tais coleções de traços, gestos e cores, um lugar valorizado e visível na cultura e no mundo das artes. Aqui, não importa classificar e denominar, segundo critérios marcados pelas dicotomias e separações, o que pode ser considerado parte da cultura ou dela excluído. Nosso olhar recai em um longo horizonte, e não encontra demarcação de beiras, como se as obras e seus artistas vivessem em meio a um grande rio que, de tão largo, não dá a ver suas beiradas, artistas da margem e do meio, que não atracam ou se enrijecem nos lugares da moda cultural, uma vez que seu ditame de produção não corresponde a nenhum outro imperativo do que seu próprio desejo, sem finalidade mercadológica e escolástica, obras dos afectos e das singularidades, ditadas pela força de expressão de seus corpos.

Acreditamos que esse movimento se integre aos propósitos da reforma psiquiátrica e exerçam influência no processo de transformação dos espaços e dos métodos terapêuticos existentes. Da mesma maneira, poderá interceder a favor da receptividade da loucura no âmbito social, possibilitando talvez algo de uma aproximação necessária no difícil processo de reconciliação do homem com sua própria condição.

Trata-se de um plano de vida que vive por si, sem nenhuma promessa de salvação ou mudança de endereço; a Oficina mesma já é um outro endereço, constituído por essas vidas que passam, podendo se conservar e também se fazendo outras pela constituição de consistências. A consistência dessas quatro coleções merece ser tomada como um sucesso precário desses resquícios vivos da história dos homens, em se fazer durar cumprindo uma exigência imanente de criação de si numa condição definitivamente provisória. 


\section{Tania Mara Galli Fonseca*}

Psicóloga, professora titular do Instituto de Psicologia da UFRGS, docente pesquisadora dos Programas de PósGraduação em Psicologia Social e Institucional e Informática na Educação/UFRGS

\section{Andresa Ribeiro Thomazoni}

Psicóloga, mestranda em Psicologia social e institucional na UFRGS, integrante do grupo de pesquisa Corpo, Arte e Clínica nos Modos de Trabalhar e Subjetivar

\section{Vivian Lockmann}

Artista visual, graduanda em Artes Visuais na UFRGS, integrante do grupo de pesquisa Corpo, Arte e Clínica nos Modos de Trabalhar e Subjetivar

\section{Vitor Butkus}

Artista visual, graduando em Artes Visuais na UFRGS, integrante do grupo de pesquisa Corpo, Arte e Clínica nos Modos de Trabalhar e Subjetivar

\section{*Endereço para envio de correspondência:}

Rua Campos Salles, 262 Bairro Boa Vista, Porto Alegre - RS - Brasil, CEP: 90480-030

E-mail: tfonseca@via-rs.net

Recebido 15/02/2008 Reformulado 15/09/2008 Aprovado 25/09/2008

Augé, M. (2003). Não-lugares: introdução a uma antropologia da supermodernidade. Campinas, SP: Papirus.

Benjamin, W. (1997). Obras escolhidas II. Rua de mão única. São Paulo: Brasiliense.

Bergson, H. (1959). L'évolution créatrice. Paris: Les Presses Universitaires de France.

Costa, L. A. (2005, janeiro/junho). As coleções da loucura e seus espaços: do esquadrinhamento nosográfico ao acervo de imagens. Episteme, 20, 93-99.

Deleuze, G., \& Guattari, F. (1996). Mil platôs - capitalismo e esquizofrenia (Vol. 3). Rio de Janeiro: Ed. 34.

Engelman, S. (2007). O campo de exceção e a vida nua. In T. M G. Fonseca, S. Engelman, \& C. M. Perrone, Rizomas da reforma psiquiátrica: a difícil reconciliação. Porto Alegre: Sulina.

Ferraz, M. H. C. T. (1998). Arte e loucura: limites do imprevisível. São Paulo: Lemos.

Fonseca, T. M. G. (2005, janeiro/junho). Imagens que não agüentam mais. Episteme, 20, 101-110.

Fonseca, T. M. G. (2007). Cartografias da arteloucura: insurgência de um outro espaço. In T. M. G. Fonseca, S. Engelman, \& C. M. Perrone, Rizomas da reforma psiquiátrica: a difícil reconciliação (pp. 141-180). Porto Alegre: Sulina.

Foucault, M. (2001). Outros espaços. In M. Foucault, Estética: literatura e pintura, música e cinema - Ditos e escritos III (pp. 411-422). Rio de Janeiro: Forense Universitária.

Frayze-Pereira, J. A. (2003). Nise da Silveira: imagens do inconsciente entre psicologia, arte e política. Estudos Avançados, 17(49), 197-208. Recuperado em 14 de maio de 2007, de http://www.scielo.br/scielo.php?script $=$ sci arttext\&pid $=$ S0103-40142003000300012\&lng =pt\&nrm $=$ isso

Janeira, A. L. (2005, janeiro/junho). A configuração epistemológica do coleccionismo moderno (séculos XV-XVIII). Episteme, 20, 23-36.

Vilela, E. (2000). Corpos inabitáveis: errância, filosofia e memória. Enrahonar: Quaderns de Filosofía, 31, 35-52.

Weinreb, M. E. (2003). Imagem e desrazão: estudos sobre a produção plástica de Manoel Luis da Rosa (1961- 2002). Dissertação de Mestrado em Artes Visuais, Universidade Federal do Rio Grande do Sul, Porto Alegre. 